\title{
Testing the Cointegrating Relationship between Health Care Expenditure and Economic Growth in Nigeria
}

\author{
Ayoola Sunkanmi Odubunmi ${ }^{1}$, Jimoh Olakunle Saka ${ }^{1} \&$ David Mautin Oke ${ }^{1}$ \\ ${ }^{1}$ Department of Economics, Faculty of Social Sciences, Lagos State University, Ojo, Lagos, Nigeria \\ Correspondence: Ayoola Sunkanmi Odubunmi, Department of Economics, Faculty of Social Sciences, Lagos \\ State University, Ojo, Lagos, Nigeria. Tel: 234-803-327-5274. E-mail: s.odubunmi2007@yahoo.com
}

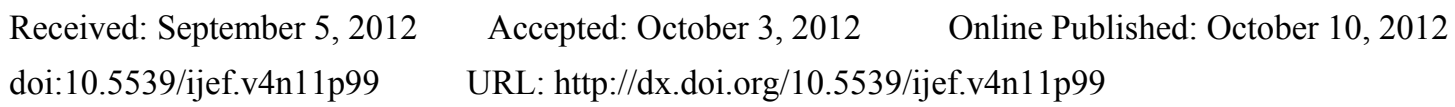

\begin{abstract}
This paper examined the relationship between health care expenditure and economic growth in Nigeria for the period 1970-2009. We employed the multivariate cointegration technique proposed by Johansen and found the existence of at least one cointegrating vector describing a long run relationship among economic growth, foreign aids, health expenditure, total saving and population. This is further confirmed by the Hassen Parameter instability test. The cointegrating equation however shows some deviations in terms of the signs of the coefficients of foreign aids and health expenditure which partly may be attributed to some diversification of foreign aids to other uses or that the allocation to health services is grossly inadequate. It is therefore suggested that an appreciable proportion of the national budget be allocated to the health care services to have a more robust health care programmes capable of fostering economic growth in Nigeria.
\end{abstract}

Keywords: health care expenditure, economic growth, co-integration

JEL classifications: C32, I15

\section{Introduction and the Background}

The significance of health especially to human capital has been well documented. The World Health Organization (WHO, 2005) attributed the fifty per cent differentials in economic growth between developed and developing nations to Health Care and this is a pointer to the fact that there is a positive correlation between health care and economic growth. Health outcomes are affected by a wide range of factors, pertaining to the individual, social and environmental context. In addition, preventive and curative health services are direct inputs that affect an individual's health status and the ability to cope with ill health (Benefo and Schulz, 1994).

Given the importance of health services, policy makers in Nigeria have been giving considerable attention to the issue of how public expenditure on health can be increased so as to ameliorate health care problems. And in line with this, expenditure on health care has been on the increase since independence. The health care recurrent expenditure was $\$ 12.48$ million in 1970 , it increased to $\$ 52.78$ million in 1980 ( $322.9 \%$ ) and further rose to $\$ 132.02$ million in 1985 (150.13\% ). In 1989 and 1991 it was $\$ 5785.3$ million and $\$ 668.40$ million respectively. The budgeted expenditure rose to $\$ 1.27$ billion in 2008. This shows that expenditure on health has been increasing on a yearly basis. Despite this however, there is no correlation between the Health Care expenditure and Nigerian Health Status. Statistical evidence from the National Bureau of Statistics (NBS) (Various issues) reveals one hospital bed per 1,806 people in 2005, compare with one per 1,651.6 in 2001. The population per doctor and nurse ratios deteriorated from $3376: 1$ to $3059: 1$ and from 1082:1 to 714:1 respectively over the same period.

In addition, life expectancy has been the most common indicator of health conditions in a country, and Nigeria's was just 44.9 years in 2003, down from 47.5 years below those of Ghana (54.4 years) and Cameroun (48.0 years). The high rates of HIV/AIDS infection has contributed significantly to Nigeria's low life expectancy (USAID, 2010). The 2003 HIV/AIDS infection rate of 5.4 per cent remained almost unchanged in 2011. It is above the LI-SSA average (4.4 per cent) and Ghana's rate (3.1 per cent), but below that of Cameroun (6.9 per cent). On the aggregate, 3.5 million people in Nigeria are affected which translates to 10 per cent of the world's total infected population (USAID, 2010). 
Infant mortality rate (IMR) fell from 78.8 per 1,000 life births in 2002 to 76.0 in 2006 . About $52 \%$ of under five deaths are associated with malnutrition. The maternal mortality rate (MMR) is another troubling indicator, an estimated 800 deaths per 100,000 live births in 2000 and has remained almost unchanged in 2011. This rate is worse than Ghana (540 deaths) or Cameroun (730 deaths), yet slightly below the LI-SSA average of 880 . This statistics highlights Nigeria's low score on another health indicator, the percentage of births attended by a skilled health professional 35 percent in Nigeria which is low relative to the LI-SSA average of 50 percent and Cameroun's 60 percent (USAID, 2010). According to USAID (2010) the provision of basic health service is a major form of human capital investment and a significant determinant of growth and poverty reduction. Therefore, an understanding of health conditions can influence the design of economic growth and poverty reduction. USAID therefore notes that, health problems cannot be addressed in a sustainable way without more funding and initiatives on the part of government.

One of the main objectives of the World Bank's Country Partnership strategy and Nigeria's National Economic Empowerment Development Strategies Programme according to USAID (2010) is to improve these conditions to meet Millennium Development Goals (MDG), but the allocation of Nigerian government to health spending in recent years is only 0.66 percent of GDP. This expenditure is less than one-third of the regional average and also below the spending in Ghana and Cameroun.

The inadequate allocation of the national budget to the health sector is being worrisome and as such this study attempts to find answers to the following questions. How has government expenditure on health transmitted to the Nigerian economy? What is the relationship between health care expenditure and economic growth in Nigeria? The remaining parts of this paper is organised as follows. Section II examines health care financing in Nigeria while Section III is on review of related literature. Section IV presents the methodology and section V presents and analyses the results. Section VI concludes and offers some useful policy recommendations.

\section{Health Care Financing in Nigeria}

The structure of the Nigerian health system and mechanisms for its financing draw their origins from the colonial medical system. During colonial times, health services were primarily public services involving preventive health care mainly in the form of hygiene and sanitation, provided to the general populace. Financing public sector health service delivery derived largely from undertakings of and funded by the missionaries, who established Federal Budget Office (FBO) service delivery units, many of them outside the capital territory and other areas.

Figure 1 shows the government funding flows to the health care system. Within this arrangement, however, funding and referral linkages have never been clearly defined. National policies were developed not only to clarify the roles and responsibilities for the delivery of health care but also to expand options for health care financing. In spite of overall increase in resource availability in the government budget, overall allocations to the health sector decreased between 2000 and 2006. Federal government expenditure on health as a percentage of total government expenditure fell from $4.2 \%$ (2000) to 3.5\% (2004) and has not increased beyond $4.5 \%$ since 2004. As well, the total expenditure on health as a percentage of Gross Domestic Product (GDP) fell slightly between 2000-2006 (from 4:3\% to $4.1 \%$ )

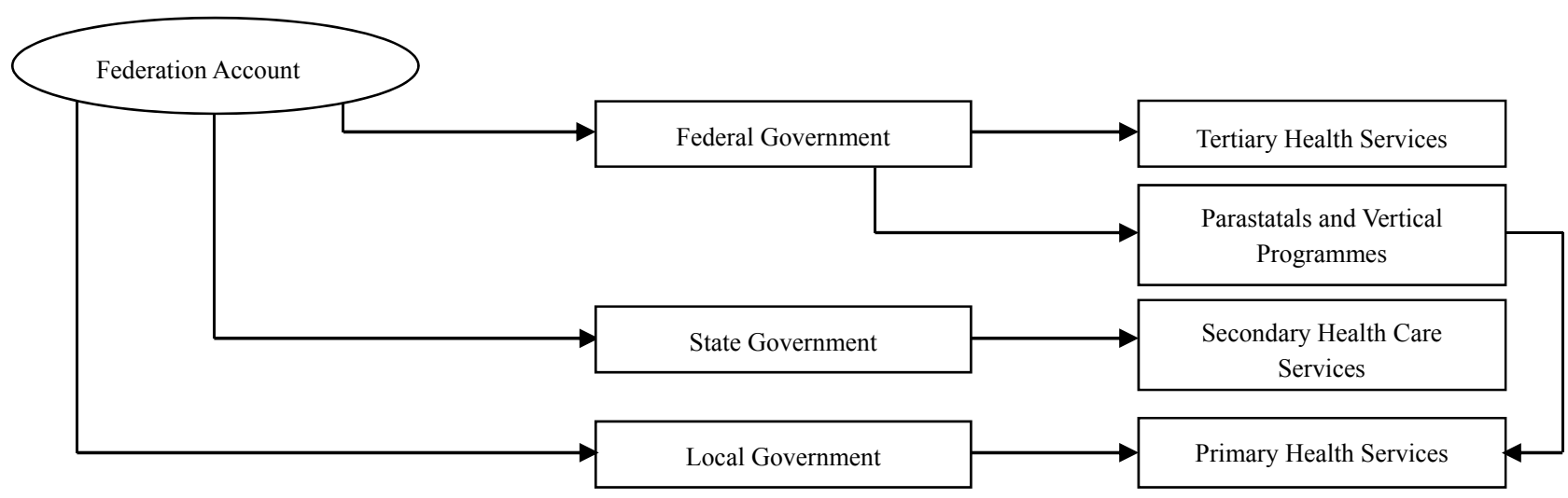

Figure 1. Government funding in health care system

Sources: Federal Ministry of Health, 2008 
Nigeria obtained relief from her group of creditors in 2005. This effort has expanded the overall fiscal space for health in Nigeria. Twenty-one per cent of its 2006 round of allocation from debt relief went to the Health Sector. In 2007 the allocation fell to $13.5 \%$, but provided further support for conditional grants and safety nets to assist both states and local governments support expansion of social service delivery, particularly primary health care (office of the Special Assistant to the President on the Millennium Development Goals, 2006, 2007).

Assessing financial flows and accountability of funds for health in Nigeria remains a dilemma because the data required for tracking resource flows, budgets and expenditure are often not easily available. The findings of Nigeria's first National Health Accounts (NHA), published in 2006 (WHO, 2006), provide important insights into the sources of health care financing in Nigeria. According to this report, household out-of-pocket expenditures remain the single largest source of health care financing constituting $65.9 \%$ of total health expenditures. This is followed by the government at $26.1 \%$ (federal $12.4 \%$, state $7.4 \%$ and local government $6.4 \%$ ),firms at $6.1 \%$ and development partners at $1.8 \%$. Per capita expenditure on health was US\$ 50.00 by 2006 (WHO, 2006).

As a part of efforts to strengthen the National Health system, the revised National Health Policy has been developed and adopted by the Federal Executive Council. The key thrusts of the policy are to expand financial options for health care and strengthen the contribution of the private sector and pre-payment based approaches for financing (Dare, 2008). It also seeks to engage communities and households in community-based schemes for the financing of primary care services. Public - Private - Partnerships (PPPs) is also presented as a strategic approach for the expansion of health financing options at all operational levels.

\section{Literature Review}

The correlation between government expenditure on health care and economic growth in Nigeria has continued to generate series of debate among scholars. According to Abdullah (2000) governments all over world are expected to perform two functions, which are protection (security) and provisions of certain public goods. In terms of protection, government is expected to enforce the rule of law, while under the provision of public goods; government is expected to provide roads, education, and health care, just to mention a few.

There have been divergent opinions on the expected relationship between government expenditure and economic growth. Some schools of thought believed that increase in government expenditure promotes economic growth (Al-Yousif, 2000; Coorcy, 2009; Barro, 1991) while other schools of thought believed that higher or increasing government expenditure may slowdown overall performance of the economy. According to them, higher expenditure might lead to increase in taxes or borrowing, whereas higher income tax discourages individual from working for long hours or even searching for jobs. The multiplier effect of this is reduction in income and aggregate demand. On the production side, higher profit tax tends to increase the cost of production which will in-turn reduce investment expenditure, therefore large government expenditure will have negative impact on economic growth (Laudau, 1983; Barro, 1991; Engen and Skinner, 1992; Folster and Henrekson, 2001).

Issues relating to the quantity of resources a country devotes to medical care have continued to get attention from researchers and policy makers. Many studies have found a strong and positive correlation between GDP of a country and the national expenditure on health care. Most studies employed a demand function approach to specify their model. In this case, the real per capita health care expenditure is expressed as a function of real per capita GDP and other selected variables

The above notwithstanding, Odior (2011) using computable general equilibrium (CGE) model found that government expenditure on health in Nigeria is significant in explaining economic growth in Nigeria and that moving resources from other sectors to provide quality health will stimulate economic growth.

Growth literature has adequately recognised the role of human capital in stimulating economic growth. The early take-off of most developed nations has largely been attributed to investment in human capital and not physical capital, thus, human capital is a key determinant of growth (Barro, 1996; Solow, 1956 and Swan, 1956).

Using infant mortality or child mortality a lot of studies found that the contribution of health care spending to health status is either small or statistically insignificant (Odior, 2011; Musgrave, 1996; Filmer and Pritchett, 1977). However, other studies have found a positive correlation between expenditure on health care and health status of the poor (Gupta et al., 2003). A micro-study by Grossman (1972), Muurinen (1982) and Wagstatt (1986) observed slight correlation between income and utilization of expenditure on health care. On the contrary, Newhouse (1977) found that over 90 per cent of the variance in per capita medical expenditure is explained by variation in per capita GDP. It was found that the income elasticity for health care spending is greater than one indicating that medical care is a luxury. 
Halil et al. (2006) in their study on tests of stationarity and cointegration of health care expenditure and gross domestic product for Turkey employed cointegration analysis to examine the long run relationship between health care expenditure, GDP and population growth .The results suggest that there exists at least one cointegrating vector especially for the total health care expenditure model.

\section{Empirical Model and Data}

The methodology here analyzes the relationship between health care expenditure and economic growth using Keynesian modelling framework which postulates that any expansion in government expenditure has positive impact on economic growth; hence the level of government expenditure on health remains an important determinant of economic growth. Based on this and following Solow (1956), an economic growth model is specified as

$$
Y_{t}=f\left(K_{t}, A_{t}, L_{t}\right)=K_{t}^{\alpha}\left(A_{t} L_{t}\right)^{1-\alpha}
$$

where $Y_{t}=$ aggregate real output, $K_{t}=$ Capital stock, $A_{t}=$ Efficiency factor, $L_{t}=$ Labour force, $\beta=1-\alpha$. Since human capital contributes positively to economic growth and following Odusola (2002) and as adopted in Olubokun and Bakare (2011), a re-specification of the model is

$$
Y_{t}=K_{t}^{\alpha} H_{t}^{\beta}\left(A_{t} L_{t}\right)^{\sigma}
$$

where $H_{t}=$ human capital. Again, an improvement in health care programmes through adequate financing schemes enhances physical and mental capabilities and thus improves productivity. Therefore, it is logical to proxy the human capital variable with health care expenditure. The natural log linear transformation of equation (2) is

$$
\ln Y_{t}=\alpha \ln K_{t}+\beta \ln H_{t}+\sigma \ln \left(A_{t} L_{t}\right) .
$$

In these equations, $\alpha, \beta$ and $\sigma$ are taken as constants and are interpreted as elasticities in equation (3).

This study employed the co-integration in analyzing the relationship between health care expenditure and economic growth as adopted by Halil et al. (2006).

Based on Engle and Granger principle, there is an underlying long run relationship between two cointegrated variables. If the two variables $X_{t}$ and $Y_{t}$ are non-stationary in their first differences, then they are $\mathrm{I}(1)$ variables so that their linear combination would be

$$
Z_{t}=X_{t}-\lambda Y_{t}
$$

If $\lambda$ exists such that $Z_{t}$ is $\mathrm{I}(0)$, then their linear combination is stationary and are therefore cointegrated even though they may drift apart in the short run. As a first step in cointegration analysis, the Philip-Perron (P-P) unit root test can be employed but we adopted the Augmented Dickey Fuller (ADF) test statistic since both techniques can approximate each other.

The ADF is

$$
\square y_{t}=a_{0}+\delta y_{t-1}+a_{2} t+\sum_{i=1}^{P} \beta i \square y_{t-i}+\mu_{t}
$$

where $y_{t}$ is the variable under consideration and the error term $\mu_{t}$ is such that

$$
\varepsilon\left(\mu_{t}\right)=0
$$

The Johansen's procedure is the main technique adopted for the test of cointegration. This avoids Engle and Granger's two step estimating and testing for the presence of multiple cointegrating vectors. It thus avoids carrying the error term introduced in the first-step estimation into the error correction mechanism. The Johansen approach relies on the relationship between the rank of matrix and its characteristic roots and estimates long-run relationship between non-stationary variables using maximum- likelihood procedure. This approach based on the rank of the coefficient matrix $\Pi$ of the equation. The test equation is of the form

$$
\Delta X_{t}=\Gamma_{1} \Delta X_{t-1}+\Delta X_{t-2}+\ldots \ldots .+\Gamma_{k-1} \Delta X_{t-1+1}+\prod X_{t-k}+\mu+\varepsilon_{t}
$$

The null hypothesis for $r$ cointegrating vector in this case is that $\Pi$ has a reduced rank, $r<k$ where $X_{t}=$ $k x 1$ vector of I(1) variables of $\Gamma_{1}, \Gamma_{2} \ldots \ldots \Gamma_{k-1} . \Pi$ is $k x k$ matrices of unknown parameters and contains 
information about the cointegrating relationship. The reduced rank condition has an implication that the process $\Delta X_{t}$ is stationary and $X_{t}$ is non-stationary. If $\Pi$ is of full rank, all elements of $X$ are stationary, if the rank of $\Pi=0$, there is absence of stationary combinations and so no cointegrating vectors and if $\Pi$ is between $r$ and $k$, the $X$ variables are cointegrated and there exists $r$ cointegrating vectors. The trace and maximum Eigen test statistics in the Johansen's approach are respectively given by

$$
\begin{gathered}
\lambda_{\text {trace }}=-N \sum \ln \left(1-\lambda_{i}\right) \\
\text { and } \lambda_{\max }(r, r+1)=-N \sum \ln \left(1-\lambda_{i+1}\right)
\end{gathered}
$$

where $\lambda_{i}$ =estimated values of the characteristics roots generated from the $\pi$ matrix, $r=$ the number of cointegrating vectors and $N=$ the number of observations

For the present case of the interaction between health care expenditure and economic growth, a measure of economic growth using the real GDP which serves as the dependent variable is adopted. This seems to have controlled for inflation uncertainty thereby explaining the real value of money. Our key independent variable is the health expenditure variable obtained as a proportion of the real GDP and which is believed to have some impact on growth. Other control variables used are population, saving and foreign aid.

The rationale for including the population variable lies on the fact that age structure is of prime importance in determining the levels of health care expenditure as the demand for medical services fluctuates with age structure. Population less than 15 years and above 65 years of age tend to utilize medical services more than the rest of the population. In between these age structures, there are the physically active population who carry the burden of the inactive populace. This amounts to stress which may affect productivity vis-a-vis growth. Our investment variable is the total saving following the classicists assumption of equality between saving and investment. If what is saved is invested under the conventional circular flow of income, then saving may determine the amount invested.

Data on foreign aid to health sector is often not readily available in most developing countries, Nigeria is no exception. An inflow of foreign capital in form of aid accentuates the rate of investment in many sectors through the provision of the foreign exchange component of investment. Aside from the salaries of health personnel, some part of health care expenditure such as the purchase of medical supplies such as imported drugs, equipment and spare parts requires foreign exchange.

On the basis of equation (3), that is, $\ln Y_{t}=\alpha \ln K_{t}+\beta \ln H_{t}+\sigma \ln \left(A_{t} L_{t}\right)$, we derive our estimating equation. In principle, we can write

$$
\ln y_{t}=\phi+\alpha \ln K_{t}+\beta \ln H_{t}+\delta_{1} \ln A_{t}+\delta_{2} \ln L_{t}+\varepsilon_{t}
$$

We have earlier taken $A_{t}$ to be the efficiency factor. In our case since foreign aid may tend to facilitate health care through provision of the required health facilities as earlier discussed, it thus serves as an efficiency factor and then may represent the $A$. On the final note, our empirical model is defined as

$$
\ln R G D P=\beta_{0}+\beta_{1} \ln K_{t}+\beta_{2} L_{t}+\beta_{3} H_{t}+\beta_{4} A D+\varepsilon_{t}
$$

where $R G D P$ is real gross domestic product capturing economic growth. The variable $K_{t}$ is proxied using total saving on the assumption that saving equal investment $L_{t}$ is proxied using the population variable serving as the labour force. The $H_{t}$ is the health care expenditure as defined earlier. We take the natural log of these variables to control for the variability among the observations and this is represented by the " $\ln " . A D=$ foreign aid although in U\$ million but is converted into Nigerian Naira to have uniformity, $\varepsilon$ is the stochastic term and $\beta_{0}, \ldots \ldots \ldots \ldots . . . . ., \beta_{4}$ are elasticity coefficients. It is expected that $\beta_{1}>0, \beta_{2}>0, \beta_{3}>0$ and $\beta_{4}>0$.

\section{Empirical Results and Discussion}

As indicated in table 1, all the variables are stationary at various levels of integration. Variables RGDP, AD and TS are stationary in their first differences as evident from the critical values test statistics $(\mathrm{CV})$ being less that the ADF test statistics in absolute terms. Only the HE, our key variable, is however stationary in its level form. This results support the claim that most economic variables are often stationary at their first differences. However, the stationarity status of the POP deviates completely from those of the rest variables as it is non-stationary even in 
its second difference. One reason that may account for this is the degree of variability among the population observations and as a result may have led to the wide spread variance.

Table 1. Unit root test results

\begin{tabular}{llll}
\hline Var & CV test stat & ADF test stat & Order of integration \\
\hline RGDP & -2.941 & -5.754 & $\mathrm{I}(1)$ \\
AD & -3.537 & -5.210 & $\mathrm{I}(1)$ \\
HE & -3.530 & -5.210 & $\mathrm{I}(0)$ \\
POP & -2.951 & 0.752 & Not even I(2) \\
TS & -3.533 & -4.348 & $\mathrm{I}(1)$ \\
\hline
\end{tabular}

Table 2. The outcome of Johansen cointegration approach

\begin{tabular}{llll}
\hline Hyp.n(CEs) & Eigen value & Trace stat & $5 \% \mathrm{CV}$ \\
\hline$r=0$ & 0.565 & 74.233 & 68.52 \\
$r \leq 1$ & 0.425 & 43.47 & 47.21 \\
$r \leq 2$ & 0.320 & 23.016 & 29.68 \\
$r \leq 3$ & 0.200 & 8.735 & 15.41 \\
$r \leq 4$ & 0.012 & 0.464 & 3.76 \\
\hline
\end{tabular}

Table 3. Cointegration result of Hansen parameter instability approach

\begin{tabular}{lllll}
\hline Lc stat & Stochastic Trends $(\mathrm{m})$ & $\begin{array}{l}\text { Deterministic } \\
\operatorname{Trends}(\mathrm{k})\end{array}$ & $\begin{array}{l}\text { Excluded } \\
\operatorname{Trends}\left(\mathrm{p}_{2}\right)\end{array}$ & Prob* $^{*}$ \\
\hline 0.4347 & 4 & 0 & 0 & $>0.2$ \\
\hline
\end{tabular}

The linear combination of the variables may however be stationary. This claim is being supported by the cointegrating relationships explored using $5 \%$ critical value. The Johansen approach in table 2 under the trace statistics indicates only one cointegrating equation testifying to the long run relationship among the variables with RGDP as the dependent variable. The parameter instability approach in table 3 further confirms this claim of long run relationship among the variables with probability value greater than 0.2 thereby accepting the null hypothesis of existence of cointegrating relationship. This finding is in line with Halil et al. (2006) on the tests of stationarity and cointegration of health care expenditure and gross domestic product for Turkey although their analysis incorporates a disaggregation of private and public expenditure on health.

On theoretical ground, we explain the long run relationship among these variables following some possible transmission mechanisms. Development assistance through provision of foreign aids would help to meet more medical needs. This would improve the health status of people all things being equal and thus enhance productivity. This is a growth enhancing channel. The cointegrating relationship motivated the existence of the error correction mechanism. As shown in table 4, the error correction coefficient has an expected negative value though not significant. It follows that about $59 \%$ of the deviation from the long run RGDP path is corrected for per period.

Table 4. Cointegrating regression and Vector Error Correction MechanismMethod: Fully Modified Least Squares(FMOLS) Dep.var $\Delta$ RGDP VECM

\begin{tabular}{llllllll}
\hline Var. & Coeff. & t-stat & Prob & Var. & Coeff. & t-stat & Prob \\
\hline AD & -0.209 & -2.299 & 0.028 & $\Delta \mathrm{AD}$ & 0.147 & 0.780 & 0.452 \\
HE & -0.472 & -2.864 & 0.007 & $\Delta$ HE & -0.130 & -0.555 & 0.590 \\
POP & 0.296 & 2.197 & 0.035 & $\Delta$ POP & 0.167 & 0.145 & 0.888 \\
& & & & & & & \\
TS & 1.246 & 2.119 & 0.000 & $\Delta$ TS & 0.039 & 0.183 & 0.858 \\
C & 1.999 & 1.723 & 0.094 & $\mathrm{ECM}_{-1}$ & -0.589 & -0.589 & 0.568 \\
& & & & & & & \\
$\mathrm{R}^{2}: 0.843$, DW: 1.12, & & $\mathrm{R}^{2}: 0.103, \mathrm{DW}: 2.44$, & & \multicolumn{2}{c}{ Long run var: 0.405} & 0.000
\end{tabular}


In the cointegrating regression using the fully modified least squares approach, all the explanatory variables are significantly related to the dependent variable RGDP at 5\% level. The variables POP and TS are negatively related to the RGDP. A 1\% per cent increase in the amount sent as foreign aid tends to decrease the RGDP by about $21 \%$. This explains the fact that such aid might not have been diverted to the channels that would foster growth and development processes and of course may also depend on priorities. The opportunity cost of diverting such aid to sectors that may not speedily facilitate growth is the appropriate diversion to the growth enhancing sectors which tends to boosts the economy. The presumed inappropriate diversion of the foreign aid might have also determined the behaviour of the health expenditure variable (HE). As the HE is increased by $1 \%$, there is a decline of about $47.2 \%$ in growth just about twice the decline in growth for a $1 \%$ increase in foreign aid. The POP and TS variables have positive impact on the RGDP. This explains the notion that a substantial numbers of active populations enhance productivity and thus growth. If saving is sufficiently translated to investment, then it adds more value to growth.

The coefficient of determination shows that the independent variables have a higher explanatory power of about $84 \%$. The DW value (1.12) demonstrates that autocorrelation is obvious among the residuals in the model. This is further confirmed by the LM test in table 5 demonstrating that serial autocorrelation is present at lag 7 (prob. $=0.068$ )

Table 5. VAR residual serial correlation LM test

\begin{tabular}{lllllllll}
\hline Lags & LM-stat & Prob. & Lags & LM stat & Prob & Lags & LM stat & Prob \\
\hline 1 & 2.494 & 0.646 & 5 & 3.182 & 0.528 & 9 & 2.304 & 0.680 \\
2 & 3.303 & 0.508 & 6 & 1.983 & 0.739 & 10 & 0.490 & 0.975 \\
3 & 3.318 & 0.506 & 7 & 8.736 & 0.068 & 11 & 0.518 & 0.972 \\
4 & 2.034 & 0.730 & 8 & 2.384 & 0.665 & 12 & 1.471 & 0.832 \\
\hline
\end{tabular}

Prob.from Chi-Square with $n=4$ where $n$ is the degree of freedom.

Table 6. VAR residual normality test

\begin{tabular}{llllllllll}
\hline component & Skewness & Chi-sq & Df & Prob & component & Kurtosis & Chi-sq & Df & Prob \\
\hline 1 & 2.766 & 47.187 & 1 & 0.000 & 1 & 13.775 & 179.001 & 1 & 0.000 \\
2 & -0.551 & 1.870 & 1 & 0.171 & 2 & 2.904 & 0.014 & 1 & 0.905 \\
Joint & & 49.057 & 2 & 0.000 & Joint & & 179.016 & 2 & 0.000 \\
& Jarque-Bera & & & & & & & \\
1 & 226.188 & & 2 & 0.000 & & & & \\
2 & 1.885 & & 2 & 0.390 & & & & & \\
Joint & 228.073 & & 4 & 0.000 & & & & & \\
\hline
\end{tabular}

The residual test for normality in table 6 indicates that it is non-normal thereby rejecting the hypothesis that residuals are multivariate normal. This increases the chance of the residuals having unit roots.

\section{Conclusion}

The paper has examined the relationship between government expenditure on health and economic growth in Nigeria. The existence of long run relationship among real gross domestic product, foreign aid, health expenditure, population and total saving is a demonstration that each of these variables is connected through some transmission mechanism.

A significant finding is that the foreign aids which tend to be supportive of the domestic investment on health facilities have not performed to expectation. The possible reason attributed to this may be the diversion of the aids to some other uses depending on the policy frame work. A very important policy option is to ensure some levels of coherence between the foreign aids and the health expenditure plans through some appreciable proportion of the budget devoted to health care services. This would pave way for better plans in health expenditure programmes thereby improving health outcomes vis-a-vis promotion of economic growth in Nigeria.

\section{References}

Abdullah, H. A. (2000). The relationship between government expenditure and economic growth in Saudi Arabia. Journal of Administrative Science, 21(2), 173-191. 
Al-Yousif, Y. (2000). Does government expenditure inhibit or promote economic growth: some empirical evidence from Saudi Arabia. India Economic Journal, 48(2).

Barro, R. (1991). Economic growth in cross-section of countries. Quarterly Journal of Economics, 106(2), 407-443. http://dx.doi.org/10.2307/2937943

Barro, R. J. (1996). Three models of health and economic growth. Preliminary Draft, Sept. http://dx.doi.org/10.1007/BF00163340

Barro, R. J. (1997). Determinant of economic growth across countries, empirical study. Cambridge: MIT Press.

Benefo, K., \& Schulz, P. T. (1994). Determinants of fertility and child mortality in Cote D' Ivory and Ghana. Living Standard Measurement Study Working Paper, Washington, D. C: World Bank.

Coorcy, A. (2009). Government expenditure, governance and economic growth. Comparative Economic Studies, 51(3), 401-418. http://dx.doi.org/10.1057/ces.2009.7

Dare, L. (2008). Situation assessment and analysis of the status of women and children in Nigeria. Health System Management, $b, 102-114$.

Engen. E. M., \& Skinner, J. (1992). Fiscal policy and economic growth. NBER Working Paper 4223.

Federal Ministry of Health. (2008). Healthreports. Various Issues, Abuja, Nigeria.

Filmer, D. J, \& Pritchett, L. (1998). Health policy in par countries: weak links in the chains. World Bank Policy Research Working Paper, No. 1874, Washington, D. C: World Bank.

Folster, S., \& Henrekson, M. (2001). Growth effects of government expenditure and taxation in rich countries. European Economic Review, 45(8), 1507-1520. http://dx.doi.org/10.1016/S0014-2921(00)00083-0

Grossman, M. (1972). On the concept of health capital and demand for health. Journal of Political Economy, 80(2), 223-225. http://dx.doi.org/10.1086/259880

Gupta, S., Verhoeven, M., \& Tiongson, E. (2003). Public spending on health care and the par. Health Economics, 12, 685-696. http://dx.doi.org/10.1002/hec.759

Halil K, Yasemin, A., \& Ahmed, D. (2006). Test of stationarity and cointegration of health care expenditure and gross domestic product: An application to Turkey.

Laudau, D. (1983). Government expenditure and economic growth: A cross country study. Southern Economic Journal, 49, 783-792. http://dx.doi.org/10.2307/1058716

Musgrave, P. (1996). Public and private roles in health: Theory and financing patterns. World Bank Discussion Paper, No. 339, Washington D. C: World Bank.

Muurinen, J. M. (1982). Demand for health: A generalized Grossman model. Journal of Heath Economics, 1(1), 5-28. http://dx.doi.org/10.1016/0167-6296(82)90019-4

National Bureau of Statistics. (2005). National Account of Nigeria. NBS: Abuja, Nigeria.

Newhouse, J. (1977). Medical-care expenditures: A cross-national survey. Journal of Human Resources, 12(1), 115- 125. http://dx.doi.org/10.2307/145602

Odior, E. S. (2011). Government expenditure on health, economic growth and long waves in a C GE micro-simulation analysis: The case of Nigeria. European Journal of Economic, Finance and Administrative Sciences, 31(1), 99-114.

Odusola, A. E. (2002). Rethinking investment and economic development in Nigeria. Nigeria Economic Society Selected Paper for the 1998 Annual Conference.

Olubokun, S., \& Bakare A. (2011). Health care expenditure and economic growth in Nigeria: An empirical study. JETEMS, 2(2), 83-87.

Sawn, T. W. (1956). Economic growth and capital accumulation. Economic Record, 32, 334-61. http://dx.doi.org/10.1111/j.1475-4932.1956.tb00434.x

Solow, R. M. (1956). A contribution to the theory of economic growth. Quarterly Journal of Economics, 70(1), 65-94. http://dx.doi.org/10.2307/1884513

United States Agency International Development. (2010). Sustaining health gains-building systems. Health Systems Report to Congress, 1- 63. 
Wagstatt, A. (1986). The demand for health: Some new empirical evidence. Journal of Health Economics, 5(3), 195-233.

World Health Organization. (2005). World health development indicators. Washington, D. C.

World Health Organization. (2006). Statistical information system. World Health Organization, WHO: Geneva. hppt./www.who.int/whosis/en 